\title{
Granulomatous myopathy: its relationship to sarcoidosis and polymyositis
}

\author{
R. H. HEWLETT AND BETTY BROWNELL \\ From the Department of Neuropathology, Frenchay Hospital, Bristol, England, and \\ Department of Anatomical Pathology, Stellenbosch University Medical School, \\ Tygerberg Hospital, Tiervlei, Cape, S. Africa
}

SYNOPSIS In three cases of generalized muscle weakness, muscle biopsy revealed well-defined, noncaseating epithelioid granulomata with giant cells. In one of these patients there was, in addition, a high serum CPK and histological evidence of widespread muscle cell degeneration and regeneration, apparently unrelated to the granulomatous process. In a re-examination of the histopathology of these cases, using biopsy material from a fourth case of proven sarcoidosis as a standard, it was concluded that there are no special features of the granulomatous/giant cell process which permit the separation of the case of presumed polymyositis. However, it appeared that granulomata per se do not exert a significant ill effect on surrounding muscle cells, and that evidence of widespread degeneration of muscle cells is the important point of distinction.

The syndrome of slowly progressive proximal muscle weakness associated with the biopsy demonstration of skeletal muscle granulomata has for long been a source of particular interest to clinicians and pathologists alike (Dyken, 1962; Gardner-Thorpe, 1972). The apparent need to provide a firm diagnosis of sarcoidosis, usually in the absence of organ involvement elsewhere, has caused stress to be laid on the interpretation of the muscle biopsy. This report presents the clinical and pathological findings in four cases of 'granulomatous myopathy', three of whom exhibited a clinical picture suggestive of chronic polymyositis, while the last showed severe muscle wasting together with a lymphadenopathy later proven to be sarcoidosis.

\section{CASE 1}

A 29 year old bantu female suffered generalized aches and pains, particularly in the hands and feet, which had commenced 12 months earlier, and for the previous five months she had noticed generalized weakness which progressed until she was unable to walk, get out of a chair unaided, or lift her arms to comb her hair. She thought that some areas of her skin were discoloured, with darkening of the face and lighten(Accepted 25 June 1975.) ing of the neck and forearms. She was anorexic and had lost weight over the past three months before admission. She denied any previous major illness such as tuberculosis.

On examination, she was apyrexial but looked ill. General examination was negative except for patchy pigmentation of the skin of the neck, and obvious generalized muscular weakness, most marked proximally. Tendon jerks were present but diminished.

The following investigations were reported as normal: haemoglobin, WBC, blood urea and electrolytes, serum proteins, serum and urinary calcium, aspartate transaminase, $\mathrm{LDH}$, aldolase and CPK, WR, ASOT, latex fixation, LE cells, porphyrins screening, and glucose tolerance. The ECG was also normal, as were the CSF and a liver biopsy. The ESR was $97 \mathrm{~mm}$ in the first hour, the chest radiograph showed possible widening of the mediastinum, and electromyography of the quadriceps femoris and biceps humeri muscles revealed a myopathic pattern.

MUSCLE BIOPSY (quadriceps femoris muscle) The striking lesion consisted of multiple granulomata, varying in size from $200-700 \mu \mathrm{m}$, and situated in connective tissue septa and within muscle fasciculi (Fig. 1). Giant cells were prominent, but no caseation or other necrosis was apparent. There were a number of myopathic changes including central nuclei and vacuolation, and also perifascicular atrophy which 


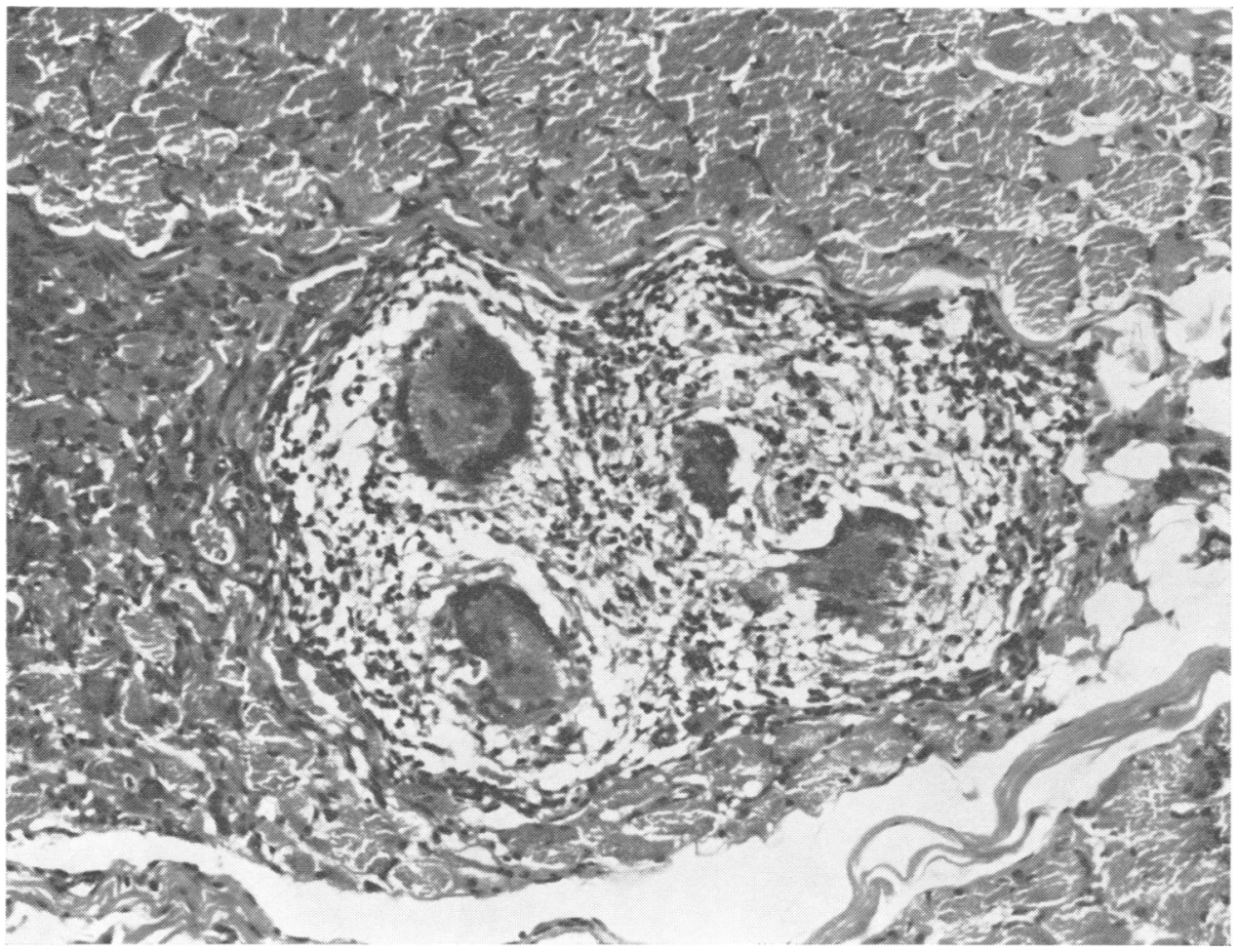

FIG. 1 Case 1. Section of quadriceps muscle showing a typical granuloma with giant cells. Haematoxylin and eosin, $\times 160$.

in one section was grouped enough to suggest denervation. Silver preparations revealed peripheral nerve involvement by a granuloma, at one point, with axonal beading and fragmentation. A minor lymphocytic infiltrate was present, usually in relation to the granulomata, and extending locally among adjacent muscle cells. Blood vessels were generally normal, and stains for tubercle bacilli and fungi were noncontributory.

COURSE AND MANAGEMENT The patient was put on to prednisone $60 \mathrm{mg}$ daily for one week, and this was reduced to $40 \mathrm{mg}$ for three weeks and she was discharged on $30 \mathrm{mg}$ daily, having shown a marked improvement in muscle power.

\section{CASE 2}

A white female, aged 72 years, was first seen in 1972 having at that time a nine months' history of an ache in the left arm, followed by progressive weakness of the limb. At the same time she noticed difficulty in climbing stairs, and over the past few months she had developed a tendency to choke when eating. Upon questioning, she admitted to having been feeling exceptionally tired for the past three years.

Examination revealed slight facial weakness and poor movement of the palate. Speech was normal, and the sternomastoid muscles did not show any weakness. There was marked wasting of the biceps and brachialis muscles bilaterally, and generalized weakness of the arms and legs, more apparent proximally. The reflexes were normal and sensation was unimpaired. There was no sign of muscular tenderness.

She had suffered a myocardial infarction two years previously, and had developed mild congestive cardiac failure as a consequence. This was treated with diuretics only.

The following investigations were reported as normal: haemoglobin, WBC, serum proteins, serum calcium, blood sugar, serum CPK, blood urea and electrolytes. The chest radiograph showed generalized pulmonary fibrosis, and the heart was slightly en- 


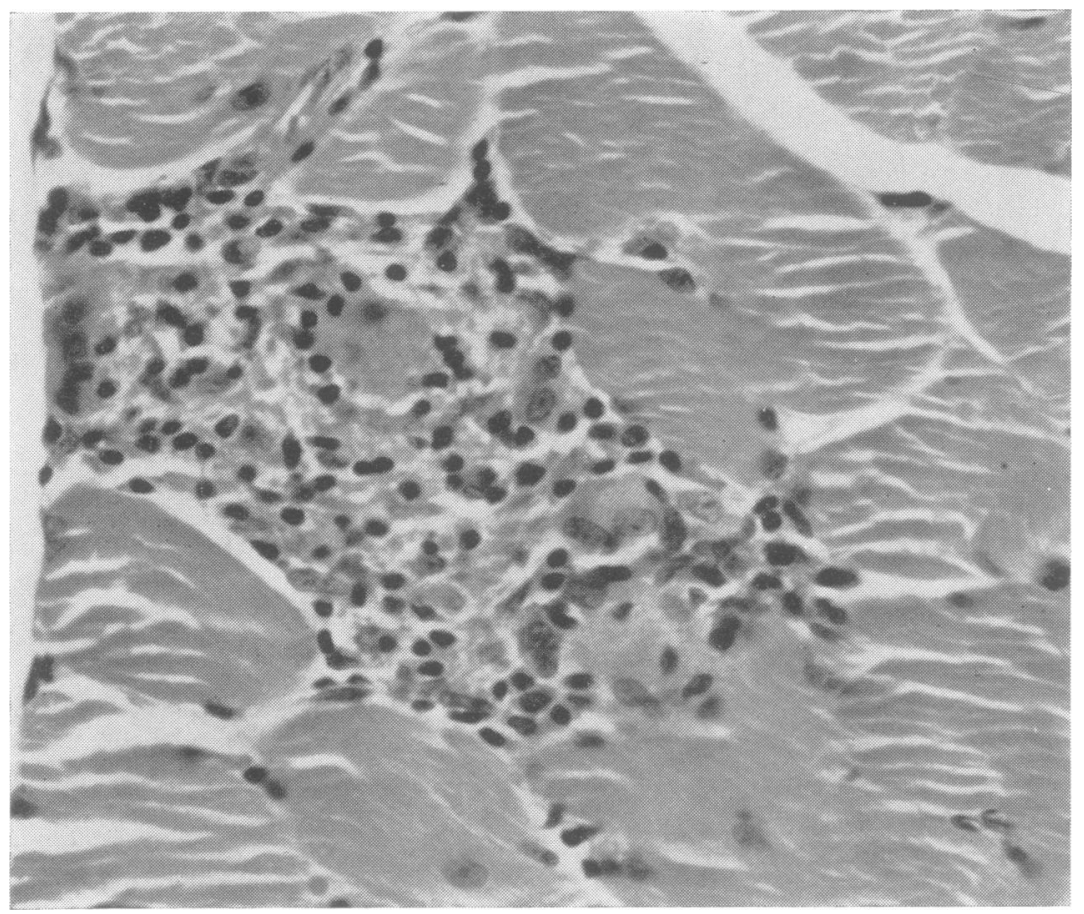

FIG. 2 Case 2. Section of deltoid muscle showing a small epithelioid granuloma surrounded by normal muscle fibres. Haematoxylin and eosin, $\times 400$.

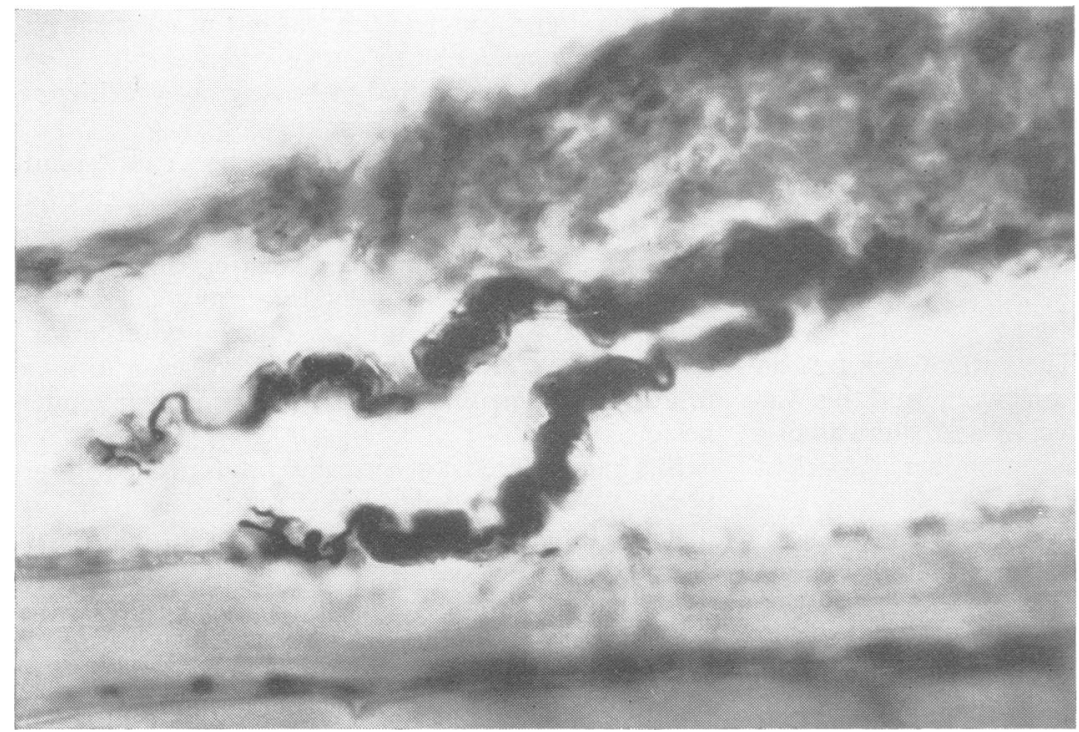

FIG. 3 Case 2. Longitudinal section of deltoid muscle showing nerve axons emerging from a granuloma. Note irregular axonal thickening, and degenerate telodendria. Schofield's modification of Bielschowsky's silver stain, $\times 400$. 




FIG. 4 Case 2. Cryostat section of deltoid muscle showing enclosed type I cells and a small area of type grouping. Lactic dehydrogenase stain, $\times 160$.

larged. Electromyography of the deltoid and quadriceps femoris muscle was also normal. An edrophonium test was negative.

MUSCLE BIOPSY (deltoid muscle) Scattered throughout the specimen, and sparse enough to require many sections for their demonstration, were tiny epithelioid granulomata (Fig. 2) measuring approximately $200 \mu \mathrm{m}$ in diameter, apparently situated between cells, and unassociated with any myopathic changes in the surrounding muscle fibres. The remainder of the sample appeared to be normal with regard to fibre size and blood vessels, but silver preparations demonstrated a generalized axonal degeneration of terminal nerve fibres and motor endplates (Fig. 3). Sometimes these terminal axons could be seen to be emerging from a granuloma. Histochemistry revealed increased numbers of enclosed cells and small areas of fibre type grouping, both with regard to type I fibres (Fig. 4). The routine methods for the demonstration of bacilli and fungi were negative.

COURSE AND MANAGEMENT The patient was discharged from hospital without any specific therapy.
She was seen again a year later, when it was thought that her muscle weakness had progressed. The serum CPK was still normal. She was put on to $15 \mathrm{mg}$ prednisone thrice daily for six months then reduced to $5 \mathrm{mg}$ thrice daily. Two years later (March 1975), without prednisone, there was marked wasting of the upper limb muscles, especially the left deltoid, and a distinctly waddling gait. She was now unable to climb stairs or to get out of the bath unaided. Steroids were discontinued on account of severe osteoporosis.

\section{CASE 3}

This young coloured male, aged 21 years, was referred by a country practitioner because his complaint of low back ache had failed to respond to various drugs (including anti-rheumatic therapy). Steroids had not been tried. His symptoms were of six months' duration, and included a feeling of weakness and fatigue in the muscles of the neck, shoulders, arms, and thighs. Exertion made his condition worse and rest improved it. He said he tended to stumble and fall easily, and that he had difficulty in 


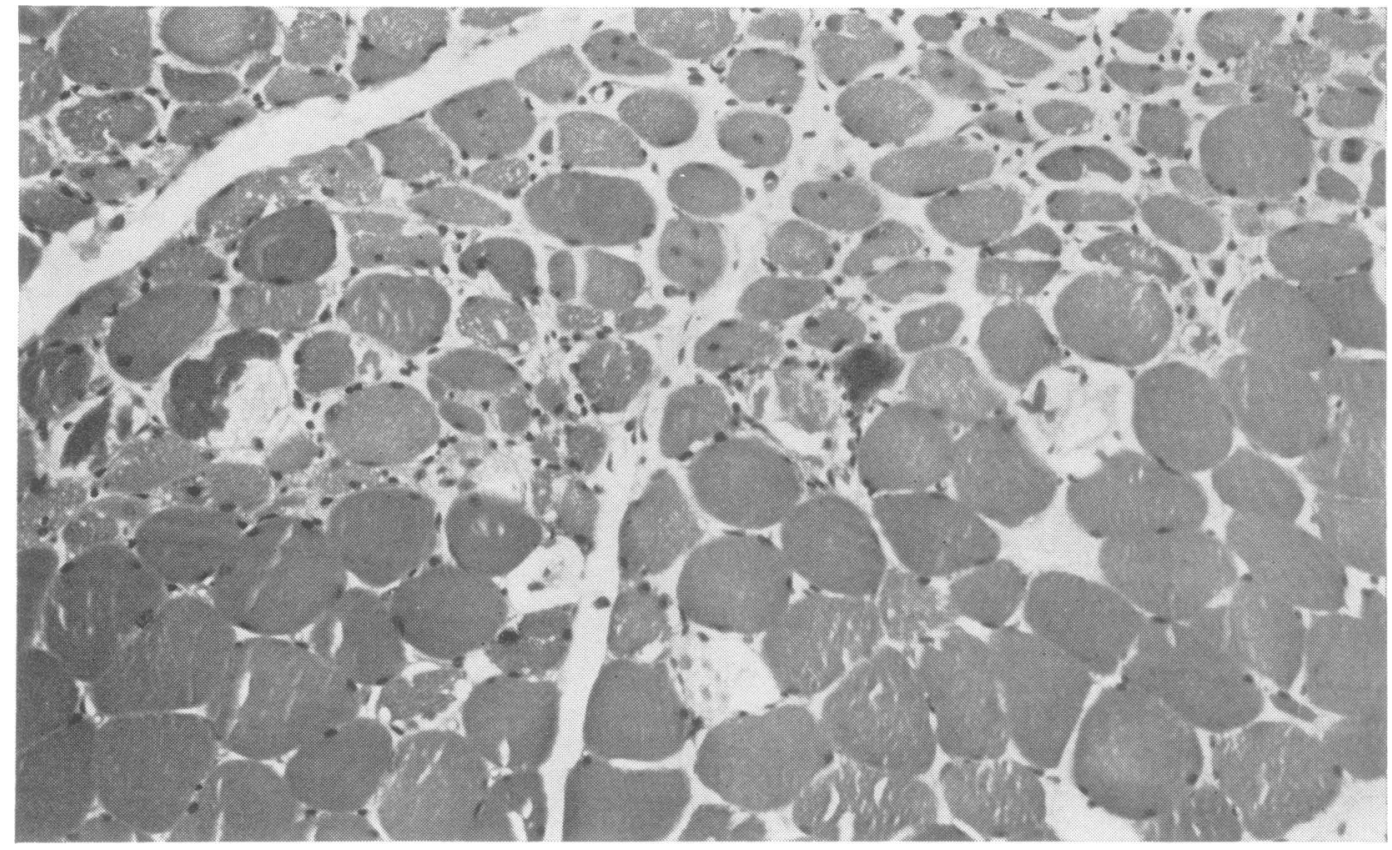

FIG. 5 Case 3. Section of quadriceps muscle showing fibre-size variation, central nuclei, and degenerating cells. Haematoxylin and eosin, $\times 160$.

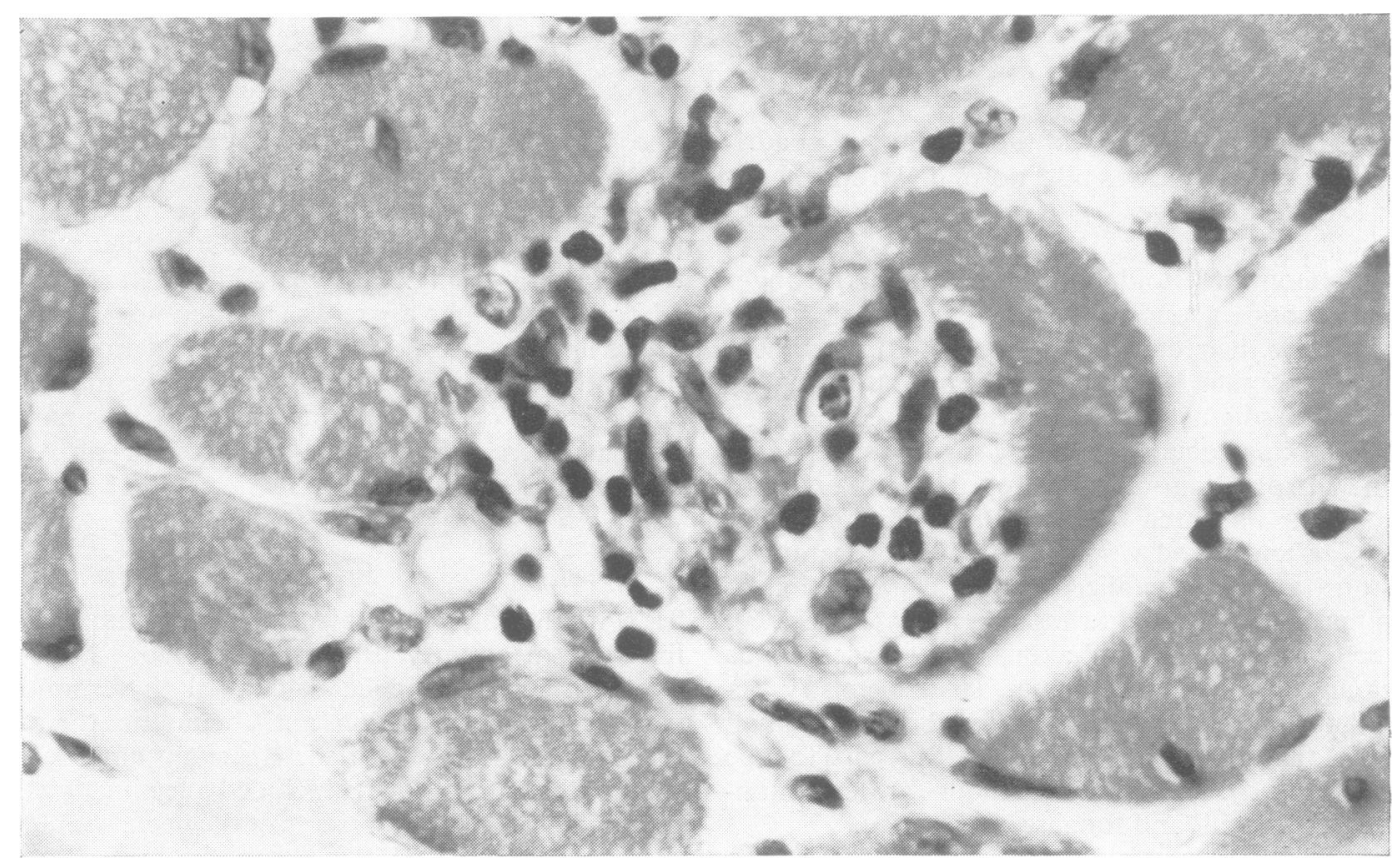

FIG. 6. Case 3. Section of quadriceps muscle showing a single tiny granuloma. Haematoxylin and eosin, $\times 640$. 
arising from the ground. On questioning, he admitted slight difficulty in swallowing solid food.

Examination revealed a slenderly built patient with minimal signs of proximal muscle wasting. The skin above the right eye was slightly erythematous. Physical signs were confined to the locomotor system, where an obvious weakness of the proximal muscles was easily demonstrable: the patient could barely lift his arms above shoulder level, and was unable to get up off the floor without assistance. Passive limb movements suggested stiffness of the muscles, but the reflexes, although somewhat diminished, were present and equal.

The following investigations were reported as normal: haemoglobin, WBC, liver function tests, blood urea, thyroid function tests, LE cells, radiography of chest and spine, and liver biopsy. The ESR was $27 \mathrm{~mm}$ in the first hour, the serum CPK 1103 IU/1 (normal 0-100), LDH 1312 IU/l (normal 0-200), and electromyography showed a myopathic pattern.

MUSCLE BIOPSY (quadriceps femoris muscle) There was evidence of a generalized myopathic process, with fibre-diameter variation, central nucleation, vacuolation, degeneration and phagocytosis, and also regeneration of muscle cells (Fig. 5). Granulomata composed of well-defined epithelioid cells were scattered sparsely through the specimen, and measured $200-600 \mu \mathrm{m}$, although very tiny lesions $(80 \mu \mathrm{m})$ could be seen (Fig. 6), apparently emanating from within muscle cells. Except for a few lymphocytes within and around the granulomata, there was no inflammatory cell infiltrate and intramuscular blood vessels were normal. Stains for tubercle bacilli and fungi were negative.

COURSE AND MANAgement Prednisone $60 \mathrm{mg}$ per day was started, and during the next six weeks the serum CPK fell to $167 \mathrm{IU} / 1$, muscle power greatly improved, and the patient was discharged on $20 \mathrm{mg}$ prednisone a day.

\section{CASE 4}

A coloured male, aged 23 years, had apparently been diagnosed as having sarcoidosis a year earlier, on the basis of a febrile illness, radiological changes in the lungs, and an adenopathy. He had been put on to steroids at one stage, but it is not known how much or for how long. He had improved on this therapy initially, but then stopped attending the outpatient department. He returned to hospital because of generalized weakness and tingling sensations in both feet.

On examination, he was found to be almost cachectic, with stocking-distribution sensory changes

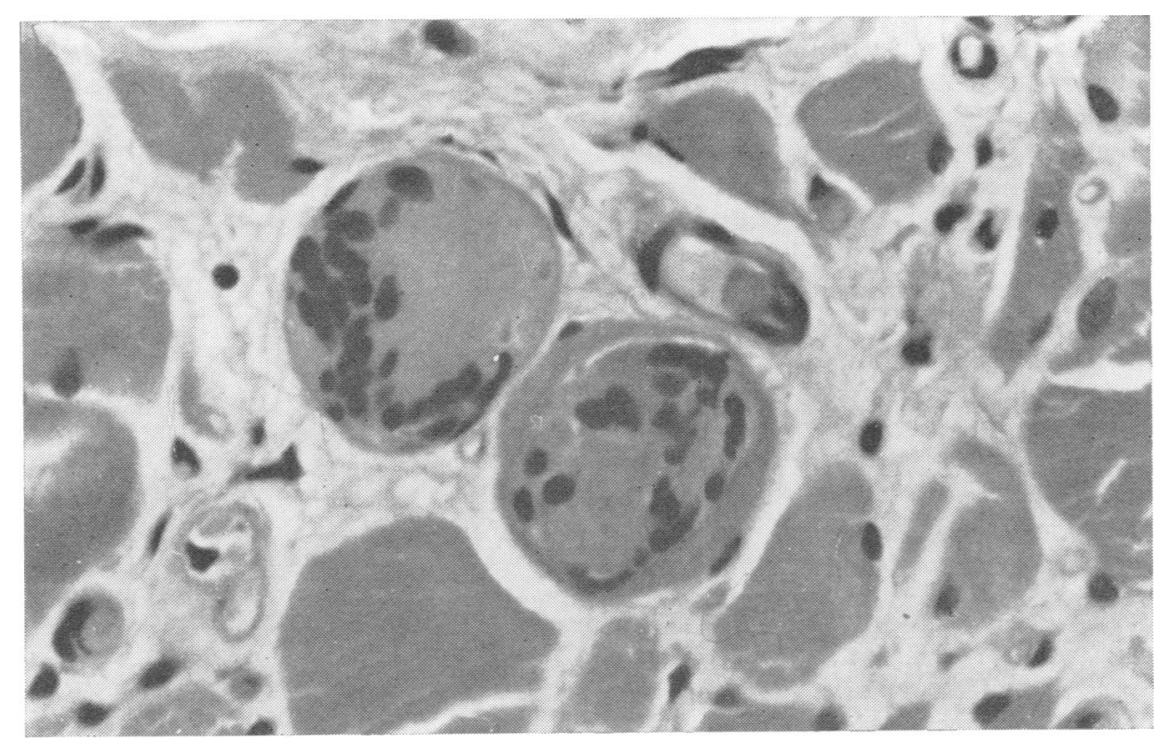

FIG. 7 Case 4. Section of quadriceps muscle showing multinucleate cells. Haematoxylin and eosin, $\times 400$. 
in both lower limbs, and absent knee and ankle reflexes. He was quite unable to walk. There was a generalized lymphadenopathy, bilateral parotid gland enlargement, and tender, swollen joints (knee, elbow).

LABORATORY INVESTIGATIONS The blood haemoglobin, serum electrolytes, serum proteins, and the CSF were normal. Serum alkaline phosphatase was markedly raised (1 $960 \mathrm{IU} / \mathrm{l})$ and the aspartate transaminase and LDH were slightly elevated. The serum CPK was normal. The ESR was $120 \mathrm{~mm}$ in the first hour, and the WBC $18000 / \mathrm{mm}^{3}$ (lymphocytes $21 \%$, monocytes $11 \%$, eosinophils $2 \%$, neutrophils $66 \%$ ). The ASO titre was 833 units. Chest radiography showed some pulmonary fibrosis suggestive of healed tuberculosis, and there was slight ECG evidence of left ventricular hypertrophy. A lymph node biopsy (done concurrently with the muscle biopsy) showed florid granulomatous inflammation without caseation. Asteroid bodies were easily seen.

MUSCLE BIOPSY (quadriceps femoris muscle) Multiple granulomata, ranging in size from $100-800 \mu \mathrm{m}$ in diameter, were apparent in many sections. The larger lesions showed multinucleate cells surrounded by epithelioid cells and lymphocytes, and were associated with obvious atrophy of adjacent muscle fibres. Occasional isolated lymphorrhages could be seen, but except for the muscle cells undergoing an apparent 'compressive' destruction by the granulomata, degenerative changes elsewhere were not apparent. Of particular interest were a number of muscle fibres in which a process of multinucleation and enlargement quite unlike simple fibre regeneration, could be seen to be taking place (Fig. 7). In what is presumed to be the early phase of this process, there was a clear demarcation between the cytoplasm of the invading cell and the muscle sarcoplasm, but when the whole structure was enlarged, the content of the cell became homogeneous. Histochemistry showed intense staining of epithelioid cells with the reduced NAD technique, evidence of myosin ATP-ase activity in multinucleate giant cells, preservation of fibre identity among those cells undergoing atrophy on the periphery of granulomata, and a general type II fibre atrophy throughout the rest of the sample. Routine methods for the demonstration of tubercle bacilli and fungi were noncontributory.

COURSE AND MANAGEMENT The patient was put back on to $45 \mathrm{mg}$ prednisone daily and showed improvement in muscle power and sensation. The serum alkaline phosphatase level fell and the lymphadenopathy was observed to diminish. He was discharged on maintenance therapy.

\section{DISCUSSION}

Examination of the literature shows very well the evolution of thought with regard to sarcoidosis and granulomatous lesions in skeletal muscle. Initially, the involvement of muscle in sarcoidosis was thought to be rare, and Ricker and Clark (1949), in a study of 300 cases, found skeletal muscle lesions in $1 \%$ of live patients and in two out of 22 necropsies. Longcope and Freiman (1952), in their excellent and widely quoted paper, do not refer specifically to muscle involvement or to clinically demonstrable muscle weakness.

Then there appeared the papers of Myers et al. (1952), Powell (1953), Phillips and Phillips (1956) and Wallace et al. (1958), from which it was concluded that sarcoidosis of muscle was relatively common, that it might be asymptomatic, and that its incidence appeared to vary directly with organ involvement elsewhere. It was pointed out that, because lesions were sparsely distributed, a number of sections might be required in order to demonstrate a granuloma.

Next it became apparent that sarcoidosis might seem to involve skeletal muscle in isolation and, in an important paper, Harvey (1959) reported, for the first time, the occurrence of a myopathic syndrome on the basis of sarcoidosis. Brun (1961) described a case of 'chronic polymyositis' as a result of muscular sarcoidosis, and Crompton and MacDermott (1961) described three cases of sarcoidosis producing progressive muscular weakness and wasting, in one of whom necropsy showed apparent regression of the muscle lesions. In 1964, Hinterbuchner and Hinterbuchner, expanding the concepts of Harvey (1959) and Brun (1961), proposed a classification for the various expressions of sarcoidosis of muscle:

1. Asymptomatic (microscopic granulomata)

2. Palpable nodules

3. Myopathic form

a. Pure myopathic without clinical evidence
of sarcoidosis
b. Myopathic with other organ involve-
ment

Thereafter, save for the sporadic account (Talbot, 1967), interest in sarcoid myopathy seems to have waned, and Scadding (1967) summarized the situation '. . . many cases of sarcoidosis involving muscles have been reported ... 
In most cases the clinical picture was that of a polymyositis with widespread weakness, usually with wasting ...'The report of Lynch and Bansal (1973) entitled 'Granulomatous polymyositis' is a good example of this syndrome; a 56 year old woman with a long history of progressive muscle weakness, having no demonstrable evidence of sarcoidosis elsewhere, a normal serum creatine phosphokinase, and a biopsy revealing muscle granulomata without evidence of generalized muscle cell degeneration. We do not support the use of the term 'polymyositis' outside the context of an inflammatory or necrotizing myopathy with widespread degeneration and regeneration of muscle cells and laboratory evidence of a collagen disease; and it is in relation to the collagenoses that we have attempted to re-examine the clinical and pathological findings in these four patients. In these circumstances, the real problem becomes one of distinguishing the myopathy of sarcoidosis from that of the collagenoses in the face of clinically identical syndromes, which may also have a similar response to steroid therapy.

Case 4 undoubtedly suffers from sarcoidosis, having a chronic illness with arthritis, parotitis, and lymphadenopathy, in addition to peripheral neuropathy, generalized muscular wasting, and a myopathic EMG. The granulomatous process has resulted in considerable local destruction of muscle cells but generalized myopathic changes, such as necrosis, phagocytosis, and infiltration by inflammatory cells, are lacking. The normal CPK excludes significant damage to muscle tissue. Case 2 probably represents the other end of the spectrum of sarcoid myopathy: muscular weakness and wasting of many months duration, generalized pulmonary fibrosis, unremarkable laboratory tests (including EMG, serum CPK), and sparse, small muscle granulomata with no myopathic changes whatever. Case 1 demonstrates an intermediate form, with severe muscle weakness (although little evidence of wasting), no other demonstrable organ or tissue involvement, a normal serum CPK, myopathic EMG, and large well-developed skeletal muscle granulomata with some myopathic changes in the form of central nuclei, vacuolation, and the occasional regenerating cell, and, in addition, some evidence of intramuscular nerve involvement.

Case 3 is different from the others in two res- pects: his biopsy specimen showed widespread and severe myopathic changes with degeneration and regeneration of muscle cells but sparse, poorly developed granulomata, and the serum CPK was greatly elevated.

Is there, therefore, any sound histopathological basis for the distinction between the sarcoid and inflammatory myopathies (leaving aside the semantic problem implicit in the term granuloma)? Clearly, the granuloma itself cannot be of much help, for it has been reported in myositis complicating thymoma (Namba et al., 1974), in carcinoma (Symmers, 1951), and in various collagenoses (Adams et al., 1962). A careful study of the granulomata in this series did not reveal any useful differences between those found in cases 1,2, and 4 on the one hand, and those in case 3 on the other, except that the latter had much fewer definitive lesions. And, while we agree with Longcope and Freiman (1952) and others that the well-developed granuloma is primarily an interstitial lesion, exerting a destructive effect by compression (Adams et al., 1962), yet we were able to find in cases 3 and 4 evidence of an apparent intracellular origin (or extension of very small lesions). It was not possible to distinguish between small and medium epithelioid fusions and multinucleate muscle cells.

Of considerably more interest and possible significance is the presence of widespread muscle cell degeneration and regeneration unassociated with the immediate effects of the granuloma. Evidence of a generalized myopathy was apparent only in case 3 where muscle cell necrosis, phagocytosis, vacuolation, and regeneration were readily identifiable, and even without the granulomata would have constituted-taking into account the myopathic EMG and greatly elevated serum CPK - perfectly adequate grounds for the diagnosis of polymyositis.

We have been impressed, while studying the literature, by the virtual absence of any specific account of a generalized myopathy in the documented material: most authors comment upon the presence of local fibre degeneration or atrophy occurring as a direct result of the granulomatous focus, but only Crompton and MacDermott (1961) describe a case with histological evidence of a diffuse myopathic process (their case 2), and it is interesting to note that this patient's muscles examined at necropsy, while 
exhibiting a diffuse inflammatory infiltrate, did not show any sign of the granulomatous process apparent in the biopsy sample taken four months previously.

Apart from the report by Lynch and Bansal (1973), there do not appear to be any other studies of the histochemistry of granulomatous myopathy: these authors noted the preservation of both types of muscle fibre, adjacent to and remote from the granulomatous foci, and they concluded that nothing useful could be learned of the histochemical characteristics of those cells making up granulomata. In our own series, histochemistry was performed on two of the four cases, one of whom (case 4) was accepted as having sarcoidosis. In this subject, we were interested to observe the weak myosin ATP-ase staining of large multinucleate cells within some granulomata, although we did not ascribe any specificity to this finding other than support for our contention that such cells cannot be positively identified as either Langhans or myogenic giant cells. Epithelioid cells stained intensely with oxidative enzyme methods, whether situated within a muscle fasciculus or a septum.

The histochemical pattern, on the other hand, revealed, in both patients, an apparent loss of the normal mosaic pattern, with significant numbers of enclosed type I cells in case 2 , and a type II fibre atrophy in case 4 . Type II fibre atrophy is now accepted as being a common and nonspecific change, apparently reflecting the 'selective susceptibility' of this cell species (Engel, 1970). This finding is particularly common in the collagenoses, including polymyalgia rheumatica and rheumatoid arthritis (Brooke and Kaplan, 1972), but its pathogenesis remains obscure. In two of our patients on whom nerve preparations were made (cases 1 and 2), there was evidence of terminal axonal degeneration, sometimes associated with obvious involvement of nerve fibres by the granulomatous process. These interesting and difficult-to-interpret findings, however, unfortunately contribute little to the attempt to separate, on morphological grounds, case 3 from the others, but there remains one outstanding distinguishing feature, and that is the greatly elevated serum CPK in this patient.

Of the literature on granulomatous myopathy due to sarcoidosis, only the papers by Talbot (1967), Gardner-Thorpe (1972), and Lynch and
Bansal (1973) provide details of the estimations of this enzyme, and all were normal. We consider it significant that the considerable destruction of muscle cells by granulomatous foci, apparent in the biopsy from case 4, was not associated with a rise in serum CPK, while case 3 , whose muscle showed sparse, small foci of epithelioid cells, exhibited a very high enzyme level which fell rapidly on steroid therapy. This suggests that the nature of the pathological process is different, and that granulomata alone cannot contribute significantly to muscle cell dysfunction.

In this re-examination of the biopsy material from four cases of granulomatous myopathy, we have to conclude that, despite its apparent acceptance, genuine granulomatous inflammation complicating the picture of polymyositis must be a rare event. In a combined series of some 370 consecutive muscle biopsies examined by us (Cape Town and Bristol), muscle granulomata were encountered in only the four cases described, but, since so few patients with suspected sarcoidosis are investigated for skeletal muscle lesions, no useful assumption can be made about their incidence. Despite GardnerThorpe's (1972) assertion that other organ involvement can usually be found in muscular sarcoidosis if one's search is thorough enough, case 3 remains unresolved. Clinical and laboratory studies failed to provide collateral evidence of sarcoid, and we were unable to convince ourselves of that point upon which the diagnosis of others has hinged-namely, the reliable distinction of myogenic and epithelioid giant cells, by whatever histological detail or method. It did appear, however, that the necrotizing element of this patient's myopathy, coupled with the high serum CPK, constituted reasonable grounds for considering a collagen disorder to be the underlying pathological process of significance in his illness.

We are grateful to Professor Walter Gordon, of Groote Schuur Hospital, Cape Town, for permission to publish details from the first case, and to Professor H. W. Weber, of Stellenbosch University Medical School, for material and clinical details from cases 3 and 4. Dr R. Langton Hewer kindly allowed us to use the details of case 2 .

\section{REFERENCES}

Adams, R. D., Denny-Brown, D., and Pearson, C. M. (1962). Sarcoidosis (Boeck-Besnier-Schaumann disease). In $\mathrm{Di}$ seases of Muscle, pp. 453-457. Hoeber: New York. 
Brooke, M. H., and Kaplan, H. (1972). Muscle pathology in rheumatoid arthritis, polymyalgia rheumatica and polymyositis. Archives of Pathology, 94, 101-118.

Brun, A. (1961). Chronic polymyositis on the basis of sarcoidosis. Acta Psychiatrica et Neurologica Scandinavica, 36, 515-523.

Crompton, M. R., and MacDermott, V. A. (1961). Sarcoidosis associated with progressive muscular wasting and weakness. Brain, 84, 62-74.

Dyken, P. R. (1962). Sarcoidosis of skeletal muscle-a case report and review of the literature. Neurology (Minneap.), 12, 643-651.

Engel, W. K. (1970). Selective and non-selective vulnerability of muscle fiber types. Archives of Neurology, 22, 97-117.

Gardner-Thorpe, C. (1972). Muscle weakness due to sarcoid myopathy: 6 case reports and an evaluation of steroid therapy. Neurology (Minneap.), 22, 917-928.

Harvey, J. C. (1959). A myopathy of Boeck's sarcoid. American Journal of Medicine, 27, 356-363.

Hinterbuchner, C. N., and Hinterbuchner, L. P. (1964). Myopathic syndrome in muscular sarcoidosis. Brain, 87, 355366.

Longcope, W. T., and Freiman, D. G. (1952). Study of sarcoidosis based on combined investigations of 160 cases including 30 autopsies from Johns Hopkins Hospital and Massachusetts General Hospital. Medicine (Balt.), 31, 1132.
Lynch, P. G., and Bansal, D. V. (1973). Granulomatous polymyositis. Journal of the Neurological Sciences, 18, 1-9.

Myers, G B., Gottlieb, A. M., Mattman, P. E., Eckley, G. M. and Chason, J. L. (1952). Joint and skeletal muscle manifestations in sarcoidosis. American Journal of Medicine, 12, 161-169.

Namba, T., Brunner, N. G., and Grob, D. (1974). Idiopathic giant cell polymyositis. Archives of Neurology, 31, 27-30.

Phillips, R. W., and Phillips, A. M. (1956). The diagnosis of Boeck's sarcoid by skeletal muscle biopsy. Archives of Internal Medicine, 98, 732-736.

Powell, L. W. (1953). Sarcoidosis of skeletal muscle-report of 6 cases and review of the literature. American Journal of Clinical Pathology, 23, 881-889.

Ricker, W., and Clark, M. (1949). Sarcoidosis. A clinicopathologic review of 300 cases, including 22 autopsies. American Journal of Clinical Pathology, 19, 725-749.

Scadding, J. G (1967). Sarcoidosis, pp. 22-25. Eyre and Spottiswoode: London.

Symmers, W. St. C. (1951). Localised tuberculoid granulomas associated with carcinoma. Their relationship to sarcoidosis. American Journal of Pathology, 27, 493-521.

Talbot, P. S. (1967). Sarcoid myopathy. British Medical Journal, 4, 465-466.

Wallace, S. C., Latte, R., Malia, J. P., and Ragan, C. (1958). Muscle involvement in Boeck's sarcoid. Annals of Internal Medicine, 48, 497-511. 